\title{
Design of 4 Dof Robot ARM Based on Adaptive Neuro-Fuzzy (ANFIS) using Vision in Detecting Color Objects
}

\author{
Trisnawan, Aceng Sambas, Misbahul Jannah, Darmawan Setia Rahayu, \\ Mustafa Mamat, Mohamad Afendee Mohamed, WS Mada Sanjaya
}

\begin{abstract}
In this paper, the design of robot arm mechanics uses 4 servo which is then said to be 4 DOF (degree of freedom). With the Arduino microcontroller used, it will regulate the movement of the arm 4 DOF robot as a base servo, shoulder servo, hand servo and grip servo. Adaptive Neuro Fuzzy Inference System (ANFIS) was applied in this arm 4 DOF robot model in the detection of colored objects. Assisted with programming to perfect the system that is applied to the Arduino microcontroller so that it can do color detection and color object retrieval. As a result, the design of DOF arm 4 robots using vision can take colored objects precisely.
\end{abstract}

Index Terms: robot arm, Adaptive Neuro Fuzzy Inference System, inverse kinematic model, color detection

\section{INTRODUCTION}

We can distinguish types of robots into two types based on the control process, namely controlled robots or teleoperated robots and automatic robots (autonomos robots) [1-6]. And now there are many forms of robots made, including Humanoid Robots, Mobile Robots, Flying Robots, and Animal Robots [7-9]. Judging from the arms arm, we can classify the Arm robot, namely Revolute Robot, Anthropomorphic Robot, Cartesian Robot, Gantry Robot, Cylindrical Robot, Spherical Robot, Polar Robot, Selective SCARA Compliance Assembly Robot Arm (SCARA) [10-11]. In Robot arm, name the arm structure and servo position for determining robot arm mechanics namely Arm Base (Azimuth), Arm Shoulder, Arm Frame, Arm Elbow, Arm Hand, and Arm Finger [12-14].

Revised Manuscript Received on April 25, 2019.

Trisnawan, Department of Mechanical Engineering, Universitas Muhammadiyah Tasikmalaya, Indonesia

Aceng Sambas, Department of Mechanical Engineering, Universitas Muhammadiyah Tasikmalaya, Indonesia

Misbahul Jannah, Department of Electrical Engineering, Universitas Malikussaleh, Indonesia

Darmawan Setia Rahayu, Department of Electrical Engineering, Institut Teknologi Bandung, Indonesia

Mustafa Mamat, Faculty of Informatic and Computing, Universiti Sultan Zainal Abidin, Indonesia.

Mohamad Afandee Mohamed, Faculty of Informatic and Computing, Universiti Sultan Zainal Abidin, Indonesia.

WS Mada Sanjaya, Department of Physics, Universitas Islam Negri Sunan Gunung Djati Bandung, Indonesia
In designing 4 DOF robots arm, the Arduino microcontroller is used as an open source micro-single board controller to control robot motion [15]. The Arduino Board consists of hardware that has an Atmel AVR processor, crystal or 5 volt linear regulator and oscillator. Depending on the type of Arduino owned, which can be connected to USB on a computer or PC to upload or retrieve data. Every Arduino has a pin that can be connected to other circuits or sensors. There are so many types or types of Arduino, which have certain specifications in accordance with the desired requirements.

In color detection, color image processing techniques are used, namely how color images are handled for various image processing jobs. Color image processing is divided into 3 parts, namely: Color Transformation, Spatial processing and Color Vector processing [16]. Image processing is a general term for various techniques whose existence is to manipulate and modify images in various ways. Image or image is a spatial representation of an actual object in a two-dimensional field which is usually written in cartesian coordinates xy (as a function of two variables, $\mathrm{f}$ ( $\mathrm{x}$, $\mathrm{y}$ ), and each coordinate represents the smallest signal of the object which is usually the smallest coordinate called pixel Image [17] A coordinate system specification and a subspace in the system with each color expressed by one point in it, this is the color space intended to facilitate color specifications in the form of a standard. But later, many color spaces were made aside from RGB, including: CMY / CMYK Color Space, YIQ Color Space, YcbCr Color Room, HSI, HSV, and HSL Color Space, and CIELAB Color Room [18].

In the process of processing the detected color data, it is processed through an artificial intelligence system that is neuro-fuzzy or ANFIS. In the Neuro-Fuzzy system there are five process layers in which the functions and equations of each layer are Fuzzyfication layer, product layer, Normalization layer, Defuzzyfication layer, and Total Output Layer [19].

So in this case, the author focuses on the research of 4-DOF robots based on Adaptive Neuro Fuzzy Inference System (ANFIS), detection of color objects, built-up mechanical models, and programming to combine one system into one unit. Finally, the design of the DOF 4 arm robot works with a system that has an output to take and place colored objects. 


\section{SYSTEM OVERVIEW}

Fig. 1 describes the general flow of research on how the 4-DOF robot arm works in detecting colored objects. The system is divided into 3 systems which later become one unit.

First is in the robot assembly, the design and collection of tools and materials needed is done first. Then after the tools and materials are collected, the robot is made. The second is making programs designed to program both MATLAB and Arduino. The program design in MATLAB includes GUI, ANFIS, Serial Communication, and Robot Arm 4 DOF mechanics. And the third is taking learning data processed in Microsoft Excel with 2 Inputs and 1 Output. Then copy it in Notepad and make the file in the form (.dat). Then the file in the form (.dat) is called by anfis in MATLAB to be trained and stored as a file (.fis). The sensor used in this study is Webcam. Webcam is used to detect objects, so as to produce coordinates in $\mathrm{x}$ and $\mathrm{y}$ which are input and processed in MATLAB

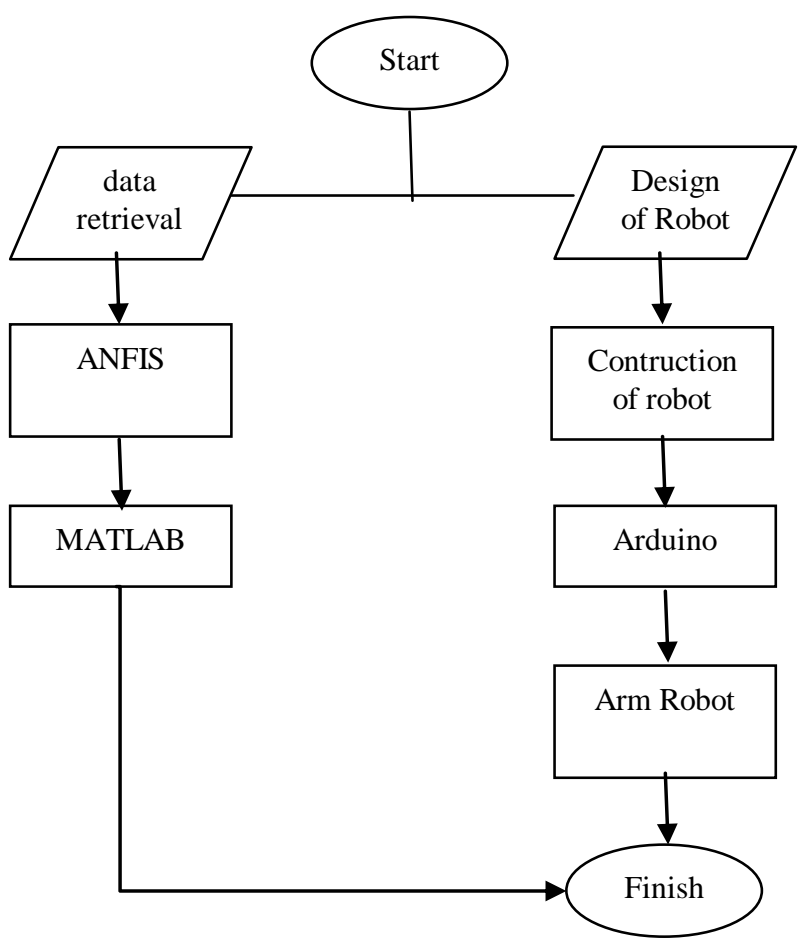

Fig. 1. General flow of research

\section{IMPLEMENTATION OF 4 DOF ARM ROBOT}

The 4 DOF robot arm that has been designed to build can be seen in Fig. 2. Basically a 4 DOF arm robot built with 4 servo axes consists of vertical and horizontal sections. These parts are base servo, servo should, hand servo, and servo grip. The design process begins by making a 4 DOF arm robot instrument and then arranging it between the instruments into one unit.

The components of the $4 \mathrm{DOF}$ arm robot consist of a microcontroller, namely Arduino, webcam, servo motor, battery, cable, box and acrylic construction that connects the servo starting from the base servo to the servo, continues to connect to the hand servo and servo grip. More details about the Robot arm 4 DOF components can be seen in Fig. 2. Sekema from the arm 4 DOF robot arm is shown in Fig. 3. All servo connected to Arduino where servo 1 is connected to pin 9 , Servo 2 is connected to pin 10, Servo 3 is connected to pin 11, and Servo 4 is connected to pin 12. While servo power obtained by connecting to a voltage source on Arduino with a GND pin and a 5 volt vec or 3.3 volt.

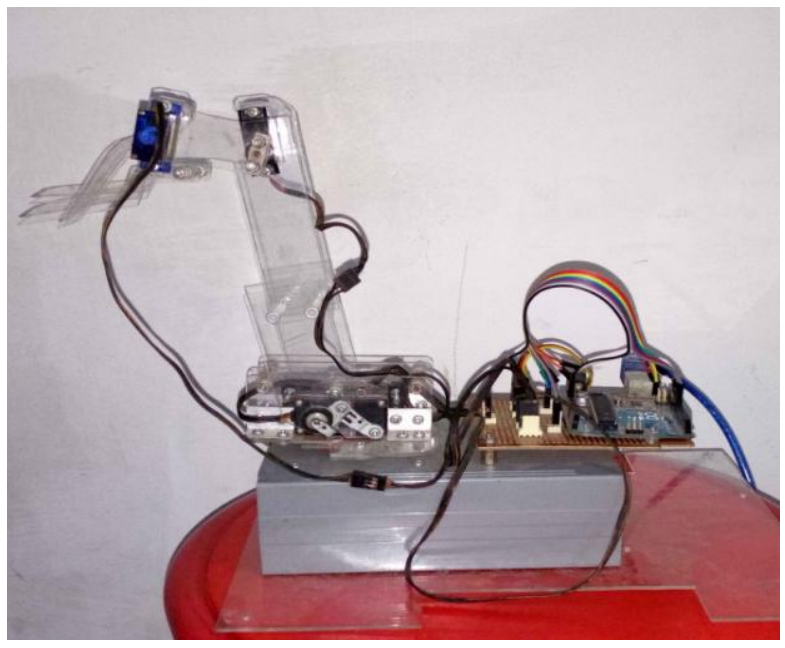

Fig. 2 Hardware of Robot Arm 4 DOF

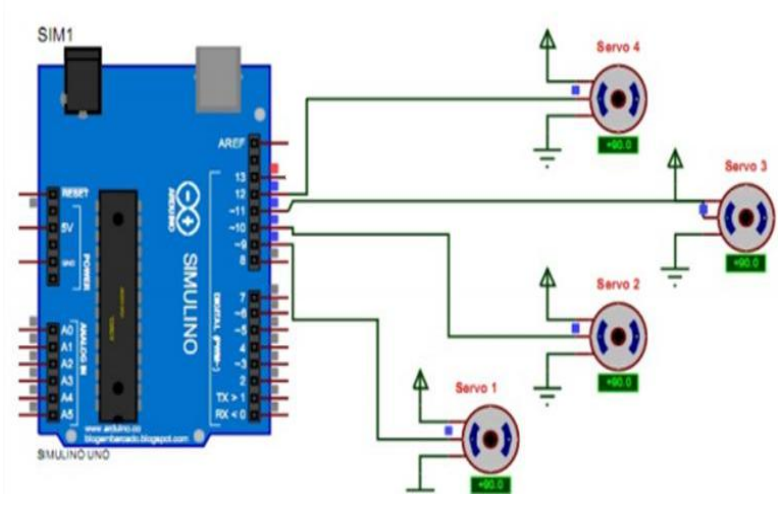

Fig. 3. Schematic of Robot Arm

\section{INVERSE KINEMATIC MODEL AND ADAPTIVE NEURO-FUZZY}

This study is based on the ANFIS method or uses the ANFIS system as learning. Neuro-fuzzy is a combination of fuzzy logic systems and artificial neural networks. The neuro-fuzzy system is based on a fuzzy inference system with learning algorithms derived from artificial neural network systems. thus, the neuro-fuzzy system has all the advantages. From its ability to learn, neuro-fuzzy systems are often referred to as ANFIS (adaptive neuro fuzzy inference systems). One form of structure that is very well known is as shown in Fig. 4.

Based on the learning data obtained, which gives servo angles to each servo, it is the result of reading the coordinates of the object detected (see Table 1). . 9 कीhis mearis, that when 
coordinates are obtained, they will be manifested or translated into their respective servo angles.

In this study, when the coordinates of objects are obtained and converted into angles for each servo motion, then in the process of translating coordinates into servo angles ANFIS is needed as a tool to process them.

The input data obtained comes from the camera or webcam from the camera pixel which becomes the coordinates, then it will be processed with ANFIS to produce output data in the form of servo angles

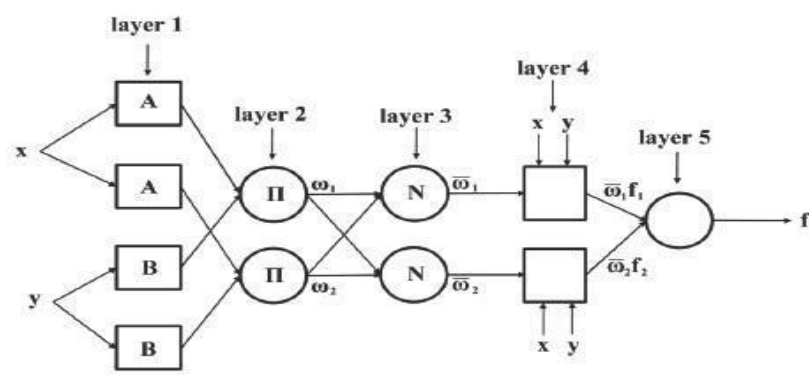

Fig. 4. ANFIS Structure

Table 1. The 4 DOF Robot Arm learning database

\begin{tabular}{|c|c|c|c|c|c|}
\hline No & $\mathbf{x}$ & $\mathbf{y}$ & $\mathbf{N o}$ & $\mathbf{x}$ & $\mathbf{y}$ \\
\hline 1 & 80 & 151 & 17 & 80 & 205 \\
\hline 2 & 105 & 151 & 18 & 105 & 205 \\
\hline 3 & 130 & 151 & 19 & 130 & 205 \\
\hline 4 & 155 & 151 & 20 & 155 & 205 \\
\hline 5 & 180 & 151 & 21 & 180 & 205 \\
\hline 6 & 205 & 151 & 22 & 205 & 205 \\
\hline 7 & 230 & 151 & 23 & 130 & 205 \\
\hline 8 & 225 & 151 & 24 & 225 & 205 \\
\hline 9 & 80 & 176 & 25 & 80 & 226 \\
\hline 10 & 105 & 176 & 26 & 105 & 226 \\
\hline 11 & 130 & 176 & 27 & 130 & 226 \\
\hline 12 & 155 & 176 & 28 & 155 & 226 \\
\hline 13 & 180 & 176 & 29 & 180 & 226 \\
\hline 14 & 205 & 176 & 30 & 205 & 226 \\
\hline 15 & 230 & 176 & 31 & 230 & 226 \\
\hline 16 & 225 & 176 & & & \\
\hline
\end{tabular}

\section{IMPLEMENTATION OF COLOR DETECTION}

As in Fig. 5 (a) and Fig. 5 (b), when the camera detects a colored object, it will give the coordinates that are processed to be servo angles, so that when the execution of the robot can move towards the object then take it and move it. The results of the experiment show that the robot can move when there is an execution command in the form of an angle output that is processed by ANFIS from the coordinates provided by the camera to move the servo to retrieve colored objects.

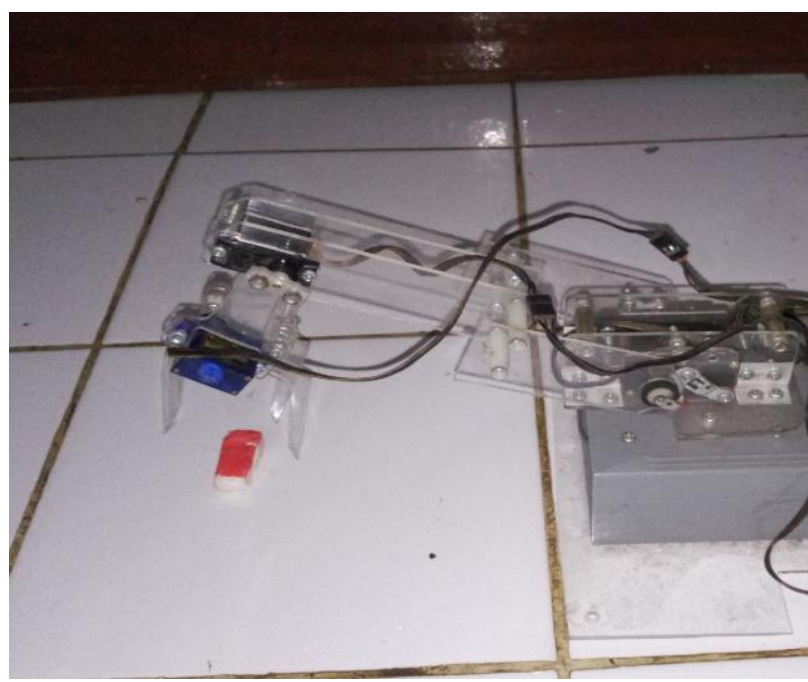

(a)

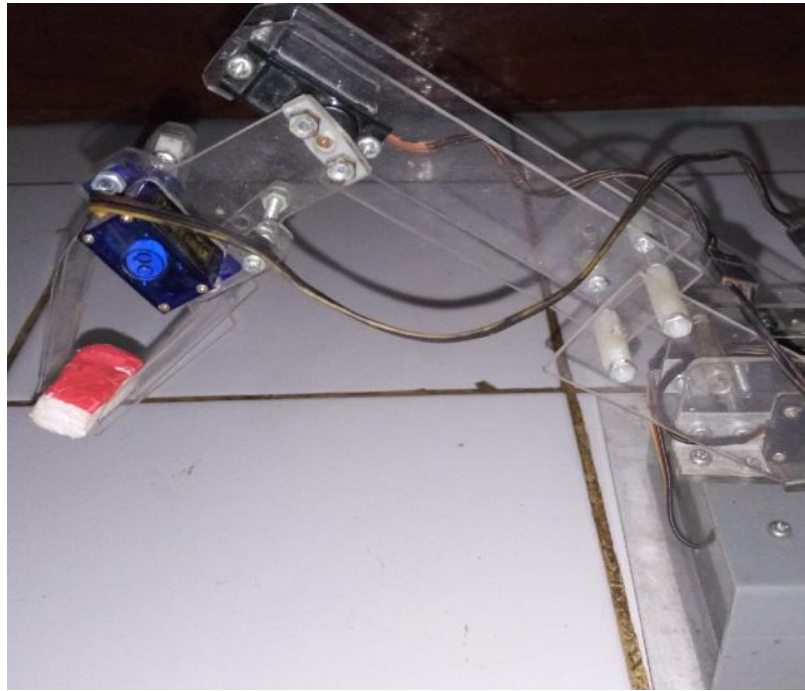

(b)

Fig. 5. Experimental result of the arm robot (a) Find colored object and (b) Pick colored object

\section{CONCLUSION}

In this work, ANFIS has been utilized to obtain the solution of inverse kinematic problem of 5 DOF robot arm. In this approach, invers kinematics relations of robot are used to obtain the data for training of ANFIS. Image processing been processed by algorithm based on MATLAB to detection of colored object. Finally, the implementation of red color detection and coordinate to control $5 \mathrm{DoF}$ of Robot Arm based on Arduino microcontroller works effective to take and place the colored object.

Published By:

Blue Eyes Intelligence Engineering \& Sciences Publication 


\section{ACKNOWLEDGMENT}

The author Trisnawan was supported by Penelitian Dosen pemula (PDP) research Grant No. 0805/K4/KM/2018 from Ministry of Research, Technology and Higher Education of the Republic of Indonesia (KEMENRISTEKDIKTI) 2018. Mohamad Afendee Mohamed thank the Government of Malaysia for funding this research under the Fundamental Research Grant Scheme(FRGS/1/2018/ICT03/UNISZA/02/ 2) and also Universiti Sultan Zainal Abidin, Terengganu, Malaysia.

\section{REFERENCES}

1. D. Arifianto. Bikin Robot itu Gampang, Jakarta: Kawan Pustaka, 2011.

2. W. Budiharto. Belajar Sendiri: Membuat Robot Cerdas. Jakarta: Elex Media Komputindo, 2006.

3. M. L. Balter, A. I. Chen, T. J. Maguire and M. L. Yarmush, "Adaptive kinematic control of a robotic venipuncture device based on stereo vision, ultrasound, and force guidance." IEEE Transactions on Industrial Electronics, vol. 64, no. 2, pp. 1626-1635, 2016.

4. S. Hong and T. Asai. "Aerodynamics of Knuckling Effect Shot Using Kick-robot.” International Journal of Applied Sports Sciences, vol. 23, no. 2, pp. 1-8, 2011.

5. C. D. Onal, X. Chen, G. M. Whitesides and D. Rus. "Soft mobile robots with on-board chemical pressure generation." Robotics Research. pp. pp. 525-540, 2017.

6. C. Smith, Y. Karayiannidis, L. Nalpantidis, X. Gratal, P. Qi, D. V. Dimarogonas and D. Kragic. "Dual arm manipulation-A survey." Robotics and Autonomous systems, vol. 60, no. 10, pp. 1340-1353, 2012.

7. W. He, W. Ge, Y. Li, Y. J. Liu, C. Yang and C. Sun. "Model identification and control design for a humanoid robot." IEEE Transactions on Systems, Man, and Cybernetics: Systems, vol. 47, no. 1, pp. 45-57, 2017.

8. A. S. Huang, A. Bachrach, P. Henry, M. Krainin, D. Maturana, D. Fox and N. Roy. "Visual odometry and mapping for autonomous flight using an RGB-D camera." Robotics Research, pp. 235-252, 2017.

9. W. Moyle, C. Jones, B. Sung, M. Bramble, S. O’Dwyer, M. Blumenstein and V. Estivill-Castro. "What effect does an animal robot called cuddler have on the engagement and emotional response of older people with dementia? a pilot feasibility study." International Journal of Social Robotics, vol. 8, no. 1, pp. 145-156, 2016.

10. N. Ahuja, U. S. Banerjee, V. A. Darbhe, T. N. Mapara, A. D. Matkar, R. K. Nirmal and S. Balagopalan. "Computer controlled robotic arm." In Computer-Based Medical Systems Proceedings. 16th IEEE Symposium, pp. 361-366, 2003.

11. F. L. Lewis, C. T. Abdallah and D. M. Dawson. Control of robot manipulators. New York: Macmillan, 1993.

12. S. K. Mustafa, G. Yang, S. H. Yeo, W. Lin and I. M. Chen, "Self-calibration of a biologically inspired 7 DOF cable-driven robotic arm." IEEE/ASME transactions on mechatronics, vol. 13, no. 1, pp. 66-75, 2008.

13. M. Shimizu, H. Kakuya, W. K. Yoon, K. Kitagaki and K. Kosuge. "Analytical inverse kinematic computation for 7-DOF redundant manipulators with joint limits and its application to redundancy resolution." IEEE Transactions on Robotics, vol. 24, no. 5, pp 1131-1142, 2008

14. J. Iqbal, R. U. Islam and H. Khan. "Modeling and analysis of a 6 DOF robotic arm manipulator." Canadian Journal on Electrical and Electronics Engineering, vol. 3, no. 6, pp. 300-306, 2012.

15. E. R. Melgar and C. C. Diez, Arduino and kinect projects: Design, build, blow their minds. New York: Apress, 2012.

16. O. Marques. Practical image and video processing using MATLAB. New Jersey: John Wiley \& Sons, 2011.

17. E. Prasetyo. Pengolahan citra digital dan Aplikasinya menggunakan MATLAB. Yogyakarta: Andi Publisher, 2011.
18. R. C. Gonzalez, R. E. Woods and S. L. Eddins. "Image segmentation." Digital image processing, vol. 2, pp. 331-390, 2002.

19. S. Kusumadewi and S. Hartati. Neuro-Fuzzy: Integrasi Sistem Fuzzy dan Jaringan Syaraf. Yogyakarta: Graha Ilmu, 2006. 